\title{
Asymmetry:
}

How Patterns of Impossibility Mark Dimensions in Knowledge Systems

\section{Mattia Paganelli}

* London, UK | Milano, Italy <-> London, UK

Dr. Mattia Paganelli is a Visiting Lecturer at the Royal College of Art, London, UK. He is also a researcher in the Data Loam project, University of Applied Arts Vienna and the Royal College of Art (London). His work concentrates on rethinking aesthetics and what may constitute the materiality of art practices in the light of the epistemological problems surrounding computational complexity, emergent properties and incompleteness. His recent work Ontology Interrupted: Prigogine, Stengers and the Abdication of Physics explores algorithmic and fractal dimensionality, feedback loops, and digital ecologies as intrinsic to the emergence of sense in contemporary art. Mattia's artistic work has been exhibited internationally and online. He has lived, studied and worked in Milan, New York, and London.
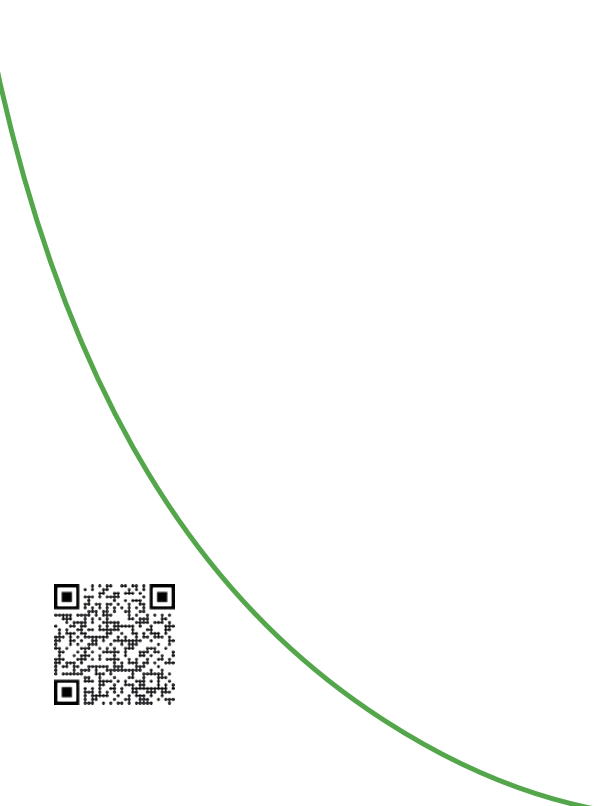
Prigogine elaborated the epistemological implications of this asymmetry in collaboration with Isabelle Stengers in several publications. My opening remarks here specifically refer to Ilya Prigogine and Isabelle Stengers (1984), "The Identification of the Real," in Order out of Chaos, Man new Dialogue with Nature, (London: Harper-Collins), vol 1, 57-78; and to Isabelle Stengers (2010 [2003 ]),

"The Science

Wars," vol 1 and

"In The Name of

The Arrow of Time:

Prigogine's Chal-

lenge," vol 2,

Cosmopolitics, translated by

Robert Bononno, (Minneapolis, MN: University of Minnesota Press), 1-83 and 105-204 respectively.

2 Bruno Latour (2005), Reassembling the Social: An Introduction to Actor Network Theory, (Oxford: Oxford University Press).

The asymmetry discussed here does not refer to the symmetry of technology and power or natural and social explanations discussed in Latour's earlier works. For that point see Bruno Latour (1993 [1991]), "Relativism," in We Have Never Been Modern, translated by Catherine Porter, (Cambridge, MA: Harvard University Press), 91-129.

\section{Prigogine's asymmetry}

The work of Ilya Prigogine and Isabelle Stengers exposes a radical asymmetry at the heart of physics: different mathematical formulations of the same problem produce equally valid yet not equivalent representations of matter and the universe. ${ }^{1}$ This chapter examines how this onto-epistemological bifurcation marks thought with the impossibility to reach past the contingency of present knowledge and yet enables a rigorous logic.

When trying to account for the coherence of sense, contemporary philosophy seems unable to let go of the habit of purging thought of all that is historical and contingent, as nothing more than noise that clouds the voice of the ontological ultimate. Prigogine's asymmetry disrupts this reductionist paradigm. Departing from the absolutist interpretations of contingency proposed by Object Oriented Ontology as well as from Latour's neo empiricist methodology, this chapter develops Prigogine's asymmetry to its most extreme consequences. ${ }^{2}$ It explains how a rigorous system of knowledge can function thanks to rather than despite of the contingent complexity of the present. The argument will revisit the thought of Descartes, Husserl, Rorty, Popper, Gödel, Deleuze, and Golding, to propose a daring reorganisation of the logic of sense that takes decidability beyond the true-false dichotomy and introduces a positive interpretation of incompleteness, by retaining rather than cleansing the contingent and entropic roughness of the present as the very condition of knowledge and the possibility of making sense. ${ }^{3}$ As will be seen, this reversal of the hierarchy between the simplicity of the ultimate and the complexity of the present shows that the patterns of possibility and impossibility encountered in knowledge systems distribute and orientate thought as dimensions logically rigorous and yet radically material. While this newly discovered materiality of knowledge is nothing new for the artist, it blows asunder the ontological edifice that keeps identity and predicate rigorously apart in the subject-object distribution of epistemology. Prigogine had sought to demonstrate that entropic irreversibility, the difference of past and future, is intrinsic to matter and cannot be reduced to the imperfection of the observer's understanding, as in classic dynamics; nor to awareness, the very act of observation and measurement, as in quantum mechanics. ${ }^{4}$ This led him to

3 Kurt Gödel (1992 [1931]), On Formally Undecidable Propositions of Principia Mathematica and Related Systems, translated by $\mathrm{B}$. Meltzer, (Mineola, NY: Dover).

\author{
4 Stengers, \\ Cosmopolitics, \\ vol 2, 101.
}


reconceptualise the second law of thermodynamics via statistical mechanics. The innovative aspect of this alternative mathematical formulation is the adoption of the function (as the expression of the rate of change in a system) rather than the equation (which represents the static boundary conditions, the system's definition or totality) as descriptor for systems with large numbers of particles-whether these are gasses, populations or epidemics. Crucially, these formulations produce diverging and yet compatible models for reality. Indeed, the pivot of Prigogine's reformulation is the system's distance from equilibrium. At or near equilibrium any state is symmetric to the boundary conditions and the system is reversible-albeit ideally. In fact, at equilibrium both formulations could be said to coincide. Far from equilibrium instead, the behaviour of systems with large numbers of particles diverges from the initial conditions with dramatic increases in information entropy. This makes large systems non-integrable, that is non reducible to the initial description, not only in practice but also mathematically. It shows that when multiplicities are involved, the approximation of finite measurements and the reduction of the complexity of the present state to an idealised and homogeneous image of matter are products of arbitrary acts of abstraction. ${ }^{5}$ In fact, for Prigogine the reducibility to an initial state would not explain but rather destroy the organisation of the present, be it a physical process or history. This exposes that physics shares the same epistemological impasse encountered in logic with Gödel's incompleteness. Undecidability, the loss of the a priori space of consistency whereby meaningful theorems/propositions are possible but cannot be explained by the original axioms alone, returns here as the irreducibility of the historical present to the systems' initial definition. 6

The problem this generates is twofold. On the one hand, the adoption of statistical mechanics reveals an epistemological impossibility internal to physics that induces a canonical paradigm shift: any form of reductionism, or symmetry between the system's description and the present state, must yield to probability as the primary unit of measurement. Temporal as well as information entropy dominate, since emergence is the expression of an augmented form of causation that exceeds the initial conditions. On the other hand-and key for the argument discussed here-this opens a much
5 The asymmetry of physical laws is not a new problem in physics. Cf Richard Feynman (2011 [1963]), "Symmetry in Physical Laws," in Six Not So Easy Pieces: Einstein's Relativity, Symmetry and Space-Time, (New York: Basic Books), 23-48.

6 Cf Ernest Nagel and James R. Newman (1986), "The Problem of Consistency," in Gödel's Proof, (New York: New York University Press), 7-24. 
7 For a detailed elaboration of this alternative, see Prigogine and Stengers, "The Identification of the Real," in Order out of Chaos, 57-78; and Stengers, "The Science Wars," in Cosmopolitics, vol 1, 1-83.

8 Prigogine and Stengers, "The Identification of the Real," 257, 285, and llya Prigogine and Isabelle Stengers (2014 [1988]), Tra il Tempo e L'Eternità, translated by Carlo Tatasciore, (Torino: Bollati Boringhieri), 139.

9 Stengers, "The Science Wars," Ibid, and see also Stengers, "The End of Tolerance," in Cosmopolitics, vol 2, 303-416. Isabelle Stengers (2000 [1993]), The Invention of Modern Science, translated by Daniel W. Smith, (Minneapolis: University of Minnesota Press).

10 Karl Popper (2002 [1935]), "Falsifiability as a Criterion for Demarcation," The Logic of Scientific Discovery, (London: Routledge), 17-20.

11 Popper, The Logic of Scientific Discovery, 315 (my italics).

12 Ibid, 19. broader and more disruptive asymmetry at ontological level: the divergence between equally valid but not equivalent representations of reality does not indicate a binary bifurcation between mutually exclusive true and false theories, nor it is observed from a third external and neutral Archimedean point. Rather, this divergence is produced by the very practice of physics. Prigogine's formulation marks epistemology with the affirmation of an alternative possibility at local level, which-as such-prohibits the convergence of different formulations onto one universal description and, therefore, undermines the image of an ontological homogeneity of knowledge. ${ }^{7}$ This undoes the expectation that science and ontology must mirror the real with symmetrical representations. What is more, Prigogine stresses that this reformulation does not impose a new universal truth, rather it presents a heterogeneous universe describable only locally-some portions are indeed reversible, while most aren't. ${ }^{8}$ Thus, the onto-epistemological asymmetry discussed by Prigogine and Stengers reopens and excludes the possibility of induction and deduction in one single gesture. While Stengers will deploy Latour's sociological interpretation to analyse this epistemological relativity, this chapter experiments with the ontological consequences of this asymmetry. ${ }^{9}$

Karl Popper's theory of refutability of scientific theories allows a particularly interesting interpretation of the asymmetry between epistemology and ontology exposed by Prigogine's work. Popper had described the criterion of demarcation of the scientific method as also asymmetric. ${ }^{10}$ Rejecting the inductive inferences of the neopositivist move, which accepted as scientific the statements that could be verified (decided) as either true or false, Popper proposed what he called a negative solution: a criterion of refutation or "falsifiability" on the base of existing knowledge, a method of "unilateral or asymmetrical or one-sided decidability."11 That is, a scientific claim must be open to be refuted by experience through empirical tests, whereas totalising universal statements are not verifiable. ${ }^{12}$ Popper emphasises that universal statements can never be derived from single local statements, while universal claims can easily be undone by a single contradictory statement. This puncturing of the image of totality (completeness) is precisely what happens in the divergence highlighted by Prigogine and Stengers. With one caveat however, and-as will be seen-here lies all the disruptive 
peculiarity of this divergence: the problem here shifts from the object of a scientific statement to the discourse that pronounces it.13 The diverging conceptualisations of the matter of physics that follow the introduction of statistical mechanics expose an irremediable fissure in the expected homogeneity of the claims of science. As Stengers points out, this non-equivalence opens an asymmetry where the "laws of physics" are not the same as the "laws of nature."14 This, she writes, leaves physics in a "fragile" state, restricting its claims from universal truths to specific "domains of validity" or "truth of the relative." 15 That is, a demonstration that shows the possibility of an alternative representation of the universe makes a homogeneous, universal and totalising description impossible. Thus, what is relevant in Prigogine's work is not what science does, but what it can no longer do. Indeed, the divergence of different conceptualisations of matter reveals that the mathematical syntax is not a neutral and transparent vehicle for representing the real but is instead opaque and creative. Crucially, the impossibility to bypass or transcend the finite syntax of mathematical formulations leads to the demise of the possibility of an absolute language of representation. In fact, it hollows the absolute of all authority. Therefore, asymmetry effects epistemology and ontology simultaneously: one argument concerns the object of physics (showing entropic irreversibility as intrinsic to matter) and is internal to the practice. The second, instead, concerns physics as a discourse, since the ontological model it projects upturns the image of knowledge as a system of compatible representations converging on one reality. What is encountered here is a disruption of what Deleuze called the image of thought. ${ }^{16}$ Asymmetry is a peculiar form of counteractualisation where a bifurcation between contingent possibilities in the practice of science prevents the image of an absolute object of knowledge from reaching the expected conclusion, or thought from being totalised. At the same time, it does not allow language to claim the authority necessary for any form of absolute representation of such an object. Indeed, a finitude without ontological boundary is, as Deleuze writes, "without image." As this divergence cannot be bypassed in any way, asymmetry marks thought and the system of knowledge with an undissolvable ontoepistemological bifurcation. However, as will be seen, this undissolvability is neither the apodictic self-evidence of non-contradiction, as

dynamic energy transfer [daI'næmik 'Enədzi 'trænsfə(:)] flow.
13 This chapter is not adopting Popper's linear image of knowledge, nor does it share Popper's trust in experience as holding the ultimate authority to confirm theoretical knowledge, or his identification of the development of science with a survival struggle. Popper's use of refutability may seem to flirt with a form of incompleteness close Gödel's argument, yet this is only a tactical stratagem. Popper is firmly intent on finding a method for the convergence of knowledge onto one reality, albeit transcendentally.

For him knowledge is attained by way of exclusion. Progressive falsifications proceed backward -so to speak-in the inductive direction, asymptotically refining a theory until this becomes true.

14 Stengers, Cosmopolitics, vol 2, 201.

15 Stengers, "Scientific

Passions," in Cosmopolitics, vol 1, 1-13. For this non-relativist interpretation of sophism see also Isabelle Stengers (2000), "Constructions," in The Invention of Modern Science, (Minnesota: University of Minnesota Press), 55-105.

16 Gilles Deleuze (2001 [1968]), "The Image of Thought," Difference and Repetition, translated by Paul Patton, (London: Continuum), 129-67. 
17 Latour, "Fourth Source of Uncertainty: Matters of Fact vs. Matters of Concern," in Reassembling the Social, 87-120.

See also Graham Harman (2009), Prince of Networks: Bruno Latour and Metaphysics, (Melbourne: Re.Press).

18 Deleuze, Difference and Repetition, 139-40.

19 Johnny Golding (2019), "The Photograph of Thought," in Daniel Rubinstein (Ed.), Fragmentation of the Photographic Image in the Digital Age, (London: Routledge), 212-23. See also J. Golding (2016), "In the Shadow of Akimbo Corporatism: Arched Athleticism and the Becoming-Human of 'a people',', in Journal of Deleuze Studies, vol 10, no. 2, 261-77.

20 René Descartes (1993 [1641]), Meditations on First Philosophy, translated by Elizabeth Haldane and G.R.T. Ross, Stanley Tweyman (Ed.), (London: Routledge), 45 (my emphasis).

21 Ibid, 51.

22 Edmund Husserl (2011 [1913]), Ideas for a Pure Phenomenology and Phenomenological Philosophy, translated by Daniel O' Dahlstrom, (Indianapolis: Hackett), 52-56. doubt in the constitution of the foundations for Descartes' cogito, nor coincides with Latour's self-professed empiricism where controversies about facts constitute the only matter of fact, nor with the claims of autonomous objects this lends itself to. ${ }^{17}$ This is also not a redeployment of the postmodern "fundamental encounter" with Being, as the "Being of the sensible" that for Deleuze "forces us to think."18 Nevertheless, as Golding writes, it provokes thought with a demand for thinking that is "neither 'natural,' 'instrumental' nor 'artificial' [and] yet, it can enable political, aesthetic and also ethic agency" by providing logical rigour. ${ }^{19}$ How the undissolvability of this asymmetric mark can force us to think by expressing a necessity, while at the same time remaining entirely contingent, is the question this chapter tries to answer.

\section{Special objects and privileged representations}

\subsection{The tabula rasa of ontological reduction}

Let us step back for a moment. Descartes opens the Meditations on First Philosophy with a statement that lays out the programme of modern thought:

"It is now some years since I detected how many were the false beliefs that I had from my earliest youth admitted as true, and how doubtful was everything I had since constructed on this basis; and from that time I was convinced that I must once for all seriously undertake to rid myself of all the opinions which I had formerly accepted, and commence to build anew from the foundation, if I wanted to establish any firm and permanent structure in the sciences."20 In the second meditation this quest leads to the tactic of doubting and to the introduction of the cogito as an undissolvable certainty built on the self-evidence of non-contradiction, which grounds thought and guarantees knowledge. However, how the cogito imposes itself is pivotal. Descartes presents this certainty as the object of a proposition whose truth is self-evident. The proposition "I exists -Descartes writes- is a necessary true proposition each time I pronounce it or think it.".21

Three hundred years later, Husserl rekindles this quest for a rigorous science by restaging the tactic of doubt as the phenomenological suspension, or epoché. ${ }^{22}$ This practice of "bracketing" knowledge does not redeploy the universal negation applied by doubt, but limits 
phenomenology to "withholding judgment." ${ }^{23}$ "I suspend all sciences related to this natural world," Husserl writes, and "I refrain from adopting a single proposition that belongs to them," keeping "theories, that is to say pre-conceptions of every kind, strictly at a distance." 24 Thus, for Husserl self-evidence becomes the experience of the world as such, reached withdrawing what he calls "natural

23 Ibid, 54 .

24 Ibid, 57.

25 Ibid, 48-50 and 56-8. apodictic truth: the "phenomenological residuum." ${ }^{25}$ Both strategies aspired to look beyond existing contingent knowledge and epistemological presuppositions, clearing the field of questioning not only of the uncertain, the doubtful, the undecidable, or the contradictory, but also of the local and finite historical roughness of scientific theories, in the hope of accessing an absolute truth that could assert itself with apodictic authority and from which the validity of everything else could be deduced. That is, both moves sought to reach certainty through a regression towards an undissolvable and self-sufficient truth. For Descartes, non-contradiction provides a barrier that stops the regress of doubting and produces the cogito, as a self-evidence that can support thought and act as a solid foothold for knowledge. Crucially, the cogito is presented as an a-dimensional point that sits outside both knowledge and thought. Husserl, instead, deploys a more complex tactic where all suspensions flow into the irreducibility of a radical epoché, or radical consciousness of Being, as an equally undoubtable residue. Here, Husserl embraces Leibniz's monadology: Descartes' ego, re-elaborated to accommodate temporality and the intersubjective objectivity of the world, becomes a transcendental consciousness, or impersonal "I," able to endow contingent experiences with necessity and to guarantee the unitary and homogeneous existence of the external world. This transcendental consciousness coincides with the disembodied gaze of Leibniz's God, an equally a-dimensional point located outside historical time and prior to individual subjectivities, exactly as Descartes' cogito. ${ }^{26}$ These moves, which encompass the horizon of the modern philosophical project, present the authority of self-evidence as an undissolvable a-historical reference point, a priori of any engagement with knowledge. Seeking rigorous foundations for science seems to require a process of epistemological stripping that places the

26 Edmund Husserl (1960 [1931]), "Second Meditation: The Field of Transcendental Experience Laid Open in Respect of Its Universal Structures," in Cartesian Meditations, An Introduction to Phenomenology, translated by Dorion Cairns, (Heidelberg: Springer), 27-55. 
27 Richard Rorty (1979), "Mirroring," in Philosophy and the Mirror of Nature, (Princeton: Princeton University Press), 129-311.

28 and the Mirror of Nature, 157, 163. problem of the undissolvable self-evidence onto a metaphysical level where reasoning is reduced to an operation of ontological cleansing. What comes to the fore is an image of foundations entirely abstract. Epistemology requires aseptic ontological foundations where necessity can express its authority only by eliminating all contingent, historical, sensual, aesthetic, and political nuances. The very fact that I think, or that the world exists, becomes a foundational principle outside the discourse and outside knowledge; a disembodied and disengaged a-historical purity from which it ought to be possible to begin always anew, each time from scratch, free from all biases. Thought must be stripped of local determinations, cleared of unverified and tentative theories, cleansed not only of obscure and confused perceptions but deprived of life altogether; emptied, that is, of its colours, flavours, sounds, desires, as well as of its ideas, traditions, histories, hopes, horrors, successes and failures. After Prigogine and Stengers this is neither so obvious nor inevitable.

\subsection{Privileged representations}

It is rather interesting and somewhat paradoxical that these aseptic foundations for a theory of knowledge are constructed, as Rorty argues, on a metaphor derived from sensorial perception. ${ }^{27}$ Rorty shows how modern philosophy presents the image of knowledge as a mirror of the world. Representation is a "quasi-visual faculty" modelled on the analogy between perception and knowledge inherited from Greek philosophy. The self-evidence on which knowledge must be constructed is conceived imitating sight, as "being brought faceto-face with the object of belief"-Rorty writes. "To know better is to understand how to improve the activity of this quasi-visual faculty, the Mirror of Nature, and thus to think of knowledge as an assemblage of accurate [visual] representations." However, as historically sensorial representations have been met with various degrees of scepticism, "the way to have accurate representations is to find within the mirror, a special privileged class of representations, so compelling that their accuracy cannot be doubted," and from which everything else can be deduced. Singling out such privileged images or representations is the task of philosophy as the theory of knowledge. ${ }^{28}$ The key for the power of these privileged representations is that the face-to-face with the natural object is interpreted as 
generating a mental image of such object. Therefore, these representations express a linear relation of physical causation, and act as a special object of knowledge able to carry its own justification. For instance, in the cogito non-contradiction is offered to reason as an object endowed with self-imposing authority. The compelling power of self-evidence is then nothing but the expression of a determinist causality, fully traceable. Accordingly, understanding amounts to retracing and keeping visible the concatenation of self-evidences that compose a demonstration, as the sequence of visible causes from the outer object to the inner image in the mind of the subject. In the case of a special object, self-evidences present a situation that cannot be otherwise and is unable to be doubted because its logical necessity is modelled as a physical cause. Reaching this evidence means reaching the metaphysical foundations of knowledge. ${ }^{29}$ The second aspect of Rorty's analysis is that in the modern demarcation of philosophy from science philosophy is presented as a "theory of knowledge" distinct from scientific statements. Only from this external position it can act as its foundations. Within this theory, truth is presented as the object of a proposition (as Descartes did), thereby conferring a great power to the language of this theory, withouthowever-addressing the ground of its authority. As Rorty writes, "knowing a proposition to be true is to be identified with being caused to do something by an object." The idea of necessity stems from the fact that "the object which the proposition is about imposes the proposition's truth." That is, belief is portrayed as the grip of a physical object upon the thinker's mind. ${ }^{30}$ The problem that emerges here is that when the causal metaphor is transposed to the truth expressed by propositions, it forces upon language a logic that does not belong to it. Objects of mathematical truth do not behave as the impenetrable bodies of dynamics, unless logic is reduced to the laws of Newtonian physics and the subject to a disembodied observer. ${ }^{31}$ Moreover, and this is crucial, this image of knowledge redeploys the principle of conservation between cause and effect, thus assuming that language is a neutral and transparent vehicle for transporting meaning. In fact, in the theory of knowledge representational language must not mingle with its content. Existence (identity) and predicate must be rigorously kept apart.32 Self-evidence can only be upheld if language does not get in the way. However, not only the
29 Rorty, Philosophy and the Mirror of Nature, 159.

30 Ibid, 157.

31 Regarding this fundamental problem of forced reduction to a universal logic see Nancy Cartwright (1983), Why the Laws of Physics Lie, (Oxford: Oxford University Press). The problem of a disembodied observer returns implicitly in Morton's autonomous objects, presented as free from a priori necessity, but identifiable and nameable only from a metaphysical position. Cf Timothy Morton (2013), Hyperobjects, Philosophy and Ecology After the End of the World, (Minneapolis, MI: University of Minnesota Press).

32 Andrea Moro (2018), A Brief History of the Verb to $B e$, translated by Bonnie McClellanBroussard, (Cambridge, MA: MIT Press). This is the contamination that Russell had hoped to avoid with the theory of types.

See Bertrand Russell (2008), "Section \$78" and "Appendix B, The Doctrine of Types," Principles of Mathematics, (London: Routledge), 80-81, 534-40, respectively. 
materiality of language has been overlooked or perhaps even censored by modern thought, but-as will be seen-the linearity of such causal representations is precisely what is interrupted by the asymmetry of syntax shown by Prigogine and Stengers.

Indeed, if in the light of the divergence exposed by asymmetry one looks again at the problem of self-evidence discussed by Rorty, it becomes clear that it is precisely the impossibility of a face-to-face evidence that marks knowledge, since asymmetry interrupts the linearity of representation conceived as the physical causation of a mental image. As the divergence of mathematical syntaxes emerges within science but affects the image of ontology, it blurs the boundaries and brings about a conflation of knowledge as an object and the theory of knowledge as its structure, as well as the collapse of the distance between the theory and the object of knowledge. That is, the impossibility to have linear representations converging onto a unitary reality due to the plural possibilities expressed in the language of science here jumps from the object of knowledge to its theory, from the predicate to the language that pronounces it. Consequently, the distinction between ontology and epistemology collapses as well. Moreover, as an alternative contingent confirmation of a theory at local level (Prigogine's demonstration) brings about the refutation of the universal image of thought (ontology), this asymmetry cannot be interpreted as a paradigm shift, as Kuhn described, rather it points to the incompleteness of all paradigms. In fact, it is greater than the paradigm of science and undermines the very possibility of a paradigm.

What this leads to is that ontology cannot expect physics to be a partner in its quest for the ultimate foundations if physics multiplies its images of matter and the universe based on the mathematical syntax of its formulations. Vice versa, if the language of science produces diverging images of the real as its objects, it cannot present itself as capable of absolute or privileged representations. To assume that there is one language that can express its object absolutely implies the disqualification of all other languages as unable to convey information correctly. Likewise, if there exists an absolute object that is supposed to be perfectly expressible through a privileged representation, then there must be an absolute language that expresses it immediately and in a complete manner without gain, loss or distortion of information. For languages less pure than the selfevidence of absolute representation, different formulations would be 
expected to converge by representing complementary portions or compatible versions of the same truth, totalisable into one continuity or projected as transcendental unity. However, with the nonequivalence of mathematical syntaxes presented by Prigogine and Stengers the absolute representational value of such language vanishes and with it crumbles the possibility of naming a homogeneous object as an arbitrary idealisation. What is disproved is not the absolute as such but, much more disruptively, the possibility of an absolute language able to represent it. Therefore, conveying selfevidence becomes impossible. Far from being a repetition of the linguistic turn, this shows that there is an inherent materiality to language, which rather than separating it from an unsayable reality shows that reality and the syntax of its representation form a continuous and non-rescindable continuity.

The issue then is how to address the problem of the compelling authority of a proposition without repeating existing answers. Neither Rorty nor Stengers' positions are fully satisfactory, though for very different reasons. On the one hand, Rorty's solution redeploys the critique already formulated by Wittgenstein: judgements rest only on other judgements, and the only escape from an infinite regression relies not on the evidence of an ultimate confirmation but on belief. Thereby reducing the coherence of sense to mere "social agreement." ${ }^{33}$ On the other, in a more cautious move, Stengers entrusts the fragility of scientific claims to a "parliament" where the experts that speak on behalf of science, having accepted that the objects of their statements are nothing but "physico-mathematical fictions," are expected to behave like diplomats. ${ }^{34}$ Here the possibilities expressedby incommensurable domains of validity would be discussed, never attempting to foreclose a question or demanding universal answers, but producing knowledge in the translation from local to public. ${ }^{35}$ While attractive, this interpretation still relies on the possibility of a virtual space of convergence as the prerequisite for the parliament's very existence. This problem may seem to have been already settled by Latour, whose method of "writing down risky accounts" of thecontroversies observed is presented as a creative practice of translation where knowledge is produced in the thickness of the text. ${ }^{36}$ Yet, this is precisely the promise that Latour does not fulfil, for it remains forever deferred. Indeed, Latour's risky accounts and Stengers'
33 Rorty, Philosophy and the Mirror of Nature, 136, 158. See also Ludwig Wittgenstein (1969), On Certainty, G. E. M.

Anscombe and G. H. von Wright (Eds.), translated by Denis Paul and G. E. M. Anscombe, (Oxford: Blackwell). Cf Ludwig Wittgenstein (1978), Remarks on the Foundations of Mathematics, G.

E. M. Anscombe, R. Rhees and G. H. von Wright (Eds.), translated by G. E. M. Anscombe, (Oxford: Blackwell).

34 Regarding Stengers' interpretation of a "polemical" logic of demarcation of science and the figure of the "diplomat," see Stengers, "Scientific Passions," in Cosmopolitics, vol I, 1-13, and "The Curse of Tolerance," in Cosmopolitics, Vol II, 303-416.

35 This ecologicalepistemological space develops Latour's "parliament of things." See Latour, We Have Never Been Modern, 142-45. For his notion of "translation," see 1-17 and 121-40.

36 Latour, "On the Difficulties of Being an ANT," in Reassembling the Social, 141-56. 
Gilles Deleuze, Difference and Repetition, 139-40. parliament remain an unarticulated black box. Which parameters would organise these mediations? What grammar would structure the translation so that diplomacy can succeed and the semantic distance does not collapse into conflict? That is, this risky practice does not lead to a freedom from deduction as Latour hoped, but to a vagueness vulnerable to the preconceptions hidden in an unquestioned adoption of representation and of the binary distribution of observer and matter-or indeed subject and object. In fact, here the problem escalates from one of methodology-as Latour posed it-to one concerning the logic of sense. Indeed, the problem of asymmetry requires a more radical answer. Finite and asymmetric domains of validity not only do not compete for the same epistemological space but depart altogether from the very ontological image of continuity as the ground for coherence, whether this is imposed as the certainty of universality or projected as the virtual possibility of agreement. In other words, as asymmetry is ineluctable because it exceeds specific representations, it jams knowledge in such a way that it imposes that one stops and thinks.

\section{What forces us to think}

At the opposite end of the spectrum from Descartes' foundations, one finds Deleuze's critique of the image of thought. Responding to the Cartesian quest for clean and clear beginning, as the inductivist space of the a priori structure of the system of knowledge, Deleuze proposes that:

"Something in the world forces us to think. This something is an object not of recognition but of a fundamental encounter. What is encountered [...] may be grasped in a range of affective tones: wonder, love, hatred, suffering. In whichever tone, its primary characteristic is that it can only be sensed. In this sense it is opposed to recognition. [...] It is not a sensible being but the being of the sensible. It is not the given but that by which the given is given." [and] "that which can only be sensed (the sentiendum or the being of the sensible) moves the soul, 'perplexes' it-in other words, forces it to pose a problem: as though the object of encounter, the sign, were the bearer of a problem-as though it were a problem." ${ }_{37}$ However, the unsurmountable divergence between epistemological and ontological propositions brought forth by Prigogine and Stengers' 
asymmetry makes this encounter a rather delicate matter. In fact, the problematic special object exposed by Rorty seems to be still at work in postmodern thought, albeit not as a representation, but as a force without a face, nameless.

As was seen, the cartesian a-dimensionality of the self-evident foundational object returns in Husserl. In "The Origin of Geometry" it becomes the uniqueness of the event's origin-opening the path towards the postmodern question about the logic of sense. ${ }^{38}$ This question is no longer concerned with a demonstration of the apodictic legitimacy of foundations, but with how to retrace and access it. Here, the origin is not a historical beginning or an initial cause, but the unique sense with which geometry was first established, the source of its meaning. In Husserl's interpretation this is still a problem of understanding. The initial self-evidence of geometrical statements (theorems) over time has become actualised into a repeated tradition, opaque and devoid of life. Rekindling the origin's meaning is possible through an a priori pure temporality (consciousness), where grasping this special object (certainty) hinges on reactivating and keeping open the concatenation of self-evidences that supports understanding from the origin to the present. The process relies on the Kantian architecture of the intellect in order to pass from what Husserl calls the present of the repeated historical tradition to the original meaning, or a-temporal transcendental idea. The postmodern interpretation of the event of sense echoes the a-dimensionality of this uniqueness. What changes is the path to access it. In fact, this approach to the origin seems better described by the leap experienced in the Kantian sublime. It skips the accountancy work of the intellect, seeking a point of contact, albeit infinitesimal and elusively tangent, between the finite sensible present and the unique event of sense. The link between Husserl and Deleuze is obviously Heidegger, who in Identity and Difference defines the event as a "singulare tantum," that which happens "not in any number but uniquely." ${ }^{39}$ Deleuze restages this a-dimensionality writing that the event is an "ontologically unique throw" and the repetition in the space this opens happens "not numerically but formally, the different rules being the form of a single ontological unique throw, the same across all occasions." ${ }^{\circ 0}$ The choice of the sublime mode is perhaps (1970 [1954)], “The Origin of Geometry," in David Carr, translated by Walter Biemel, The Crisis of European Sciences and Transcendental Phenomenology, (Evanston IL: Northwestern University Press), 353-78.

39 Martin Heidegger (1969 [1957]), Identity and Difference, translated by Joan Stambaugh, (New York: Harper \& Row), 36.

40 Difference and Repetition, 304. Deleuze further articulates this notion of uniqueness of the event in The Logic of Sense. Here the event is presented as a "unique cast from which all throws are qualitatively distinguished," (10th Series of the Ideal Game), and as the "Eventum Tantum" (25th Series of Univocity), again stating that language is a "a unique event," (26th Series of Language). Gilles Deleuze (1990 [1969]), The Logic of Sense, translated by Mark Lester and Charles Stivale, (London: Athlone Press), 64, 179 and 185 respectively. 
41 Jean-François Lyotard (1988), Peregrinations: Law, Form, Event, translated and edited by David Carroll, (New York: Columbia University Press), 11-12. most evident in Lyotard, who seeks "a rationality [...] timorously outlining the conditions for a re-reading and re-writing of Kant's division of reason." ${ }_{41}$ Conditions where "the law does summon thinking but in different, incommensurable ways." Here too, this summoning is faceless. The thinker is obliged to think by a "I don't know what," Lyotard writes, which coincides with the authority of that which for Deleuze's "forces us to think." However, the asymmetrical divergence encountered in Prigogine's work is neither an object of a proposition nor a sign for a problem whose first cause, the original expansion of the event, is always tangent to the present as the virtual. Another method of attunement is required.

\section{Asymmetry is neither an object nor a concept}

It now becomes clear why the asymmetry exposed in Prigogine's work poses such a radical question. Asymmetry is not the effect of an external cause. While it is contingent, as it emerges from the practice, it shapes thought as a dimension for reasoning. As the opacity of the mathematical syntax has a radical impact on the logic of representation, the asymmetry it induces cannot be approached as a nameable or thinkable object of a proposition. That is, the undissolvable problem exposed in the divergence does not impose itself with any form of self-evidence or ontological authority. There is no sentiendum, nothing to see beyond the finite contingency of the present.

In this undissolvable divergence thought does not encounter something compelling, rather runs into a discontinuity, the absence of an ontological perimeter, the impossibility of totalisation; in fact, the very impossibility to reach something absolutely compelling. Thus, asymmetry is not the name of a new form of self-evidence nor a gateway to self-evidence. It is not the encounter with a compelling truth, but a silence. It is not a lack, but the moment when diverging statements are pronounced in different languages, with the same validity albeit incommensurably. Asymmetry is the distance between positives local truths, yet it is not the space where this divergence takes place, or their negative. In fact, asymmetry is only the adjective describing diverging positive finite formulations, which do not converge onto the same image of reality and are therefore asymmetrical. It simply shows that ontology cannot be modelled on the image of a continuous space; that diverging plural possibilities are not mutually 
exclusive, and yet make a singular converging universality impossible. As such, asymmetry is passive: not a concept, but merely the name of diverging syntaxes. It does not impose a special object or a truth, rather it exposes the incompleteness of the ontological boundary. This passivity does not conceal the asymmetry of Deleuzean difference, as the horizon from which actualised entities diverge while it (difference) does not diverge from them. ${ }^{42}$ It names the distribution of finite positive claims pronounced by an opaque language without background.

As the opacity and creativity of the syntax exposed by Prigogine and Stengers lead to radically different conceptualisations of matter, they undermine the ability and authority of language to express the self-evidence of an absolute object. Thus, asymmetry is a problem that invests language before this can decide how to evaluate the evidence of its statements. In fact, asymmetry precedes decidability. Thus, in diverging it does not impose any fundamental truth, it simply exposes an interruption in the homogeneity of a global claim about the universe, not a recognisable void or a dialectical absence but a distribution of though. Indeed, the divergence exposed here, rather than being a self-evident object of a proposition of knowledge, is its very structure. Thus, with asymmetry what collapses is the distance between the metadiscourse of the theory of knowledge and the statements this evaluates as its objects; that is the depth of representation.

Moreover, as it belongs to the syntax of diverging contingent finite claims, asymmetry cannot be turned into a fact with independent existence, a new autonomous ontological entity. That is, as the finitude of syntactical divergences cannot name an absolute fact but is only an adjective for local claims, asymmetry does not provide a new ontological object or a metaphor for an ultimate reality. The possibility of alternative conceptualisations of matter cannot and must not be totalised into one ontological claim as the fact that the syntax diverges. Semantically asymmetry names a plurality of diverging positive possibilities (contingent open conjectures and their local refutations), but ontologically it is neither an object nor a concept. Presenting the fact that they are asymmetric as having autonomous existence would be an arbitrary abstraction, which-moreoverwould remain open to infinite regressions: the fact of the fact that, 
43 Quentin Meillassoux (2009 [2006)], After Finitude: an Essay on the Necessity of Contingency, translated by Ray Brassier, (London: Continuum). and so on. Naming a problem is not the same as obtaining a concept or an object. This is essential, because without compounding the contingent divergences of the images of matter produced by the syntax into a something, asymmetry cannot be transformed into the object of a proposition able to perform the face-to-face necessary for the self-evidence of truth, even when this truth is presented as the absence of truth. Thus, asymmetry resists a linear ontologisation that would reduce it and package it into an object of representation to be validated by the theory of knowledge.

It is very important to grasp the relevance of this resistance of contingency in order to avoid attempts, such as Meillassoux's, aimed at imposing the arbitrary reintroduction of absolute certainty. ${ }^{43}$ Necessity for Meillassoux, as for Descartes before him, is structured on non-contradiction as a proposition's object. However, Meillassoux needs to find a suitable target for doubt in the 21st century. This comes in the form of the history of philosophy itself: since Kant it has not been possible to claim that the world is either contingent or necessary (incompleteness). This openness, like asymmetry, is not an entity, so Meillassoux without further proofs turns this incompleteness (so far it has not been possible) into a totalised universal statement: it is impossible to claim contingency or necessity. At this point, having arbitrarily manipulated the openness of incompleteness into something closed, graspable and directly pronounceable, Meillassoux can re-stage the Cartesian strategy of non-contradiction, claiming that the world may be contingent or necessary but undecidability, the fact that it is impossible to determine this, is absolute; a self-evident truth presented as the object of the proposition that pronounces it. Thereby claiming a return to metaphysics with the "necessity of contingency." ${ }^{44}$ However, the fact that is a claim that can be stated and presented as the object of a proposition only if this is pronounced from outside the universe of facts it is naming; a claim both independent of language and turned into the content of discourse and knowledge. But this is precisely what Prigogine's asymmetric syntax does not allow-on pain of falling into the infinite regress of a statement that pretends to predicate its own identity. In fact, by disregarding Gödel's incompleteness Meillassoux runs into Russell's paradox of the set of all sets that cannot contain itself, or in Lyotard's words: "a phrase that refers to the totality of phrases cannot be part 
of that totality."45 The facticity claimed by Meillassoux is just another tactic of ontological cleansing, which claims that while the form in which the world exists is contingent and dispensable, the fact that it exists is necessary and thereby provides a undissolvable certainty outside thought and outside the history of knowledge. Asymmetry turns this logic inside-out, exposing instead that the contingent, the historical and the ephemeral distributions of knowledge are precisely what enables the logic of sense.

\section{Undissolvable contingency as a mark}

The negative method of demarcation proposed by Popper (the possibility of refuting but not verifying) proceeds by deduction, excluding contradictions between existing knowledge and empirical reality in a progressive refinement of the formulations of science, in order to advance inductively towards a transcendental truth. This deploys a delayed reductio ad absurdum where the last standing statement at some indefinite point in the epistemological future must be correct. However, the inferences of these deductions must themselves be subject to the same scrutiny. Moreover, as the asymmetry exposed by Prigogine and Stengers emerges from the very language of science, it cannot engage in a similar practice of progressive deduction and exclusion because the divergence belongs to the very language that would perform the tests. Therefore, as the divergence takes place entirely between alternative formulations inside existing knowledge, asymmetry is both: contingent-as it is neither caused by the hard reality of empirical facts which would refute one theory in favour of another, nor it is imposed by the authority of a metaphysical principle; and undissolvable-because there is no solution for bypassing its diverging formulations and reach an absolute truth other than attempting more formulations, which would be equally vulnerable to the opacity and materiality of the mathematical syntax. Thus, as such, the bifurcation between equally valid but not equivalent descriptions exposed by Prigogine cannot be decided, reconciled or sublated. Yet, it marks knowledge. It is a pattern, distributed without any recurse to metaphysical foundations, virtual origin or immanent solutions. Moreover, this contingent undissolvability is not undermined but reinforced by the very possibility of a refutation of Prigogine's alternative formulation. Indeed, if that were the case the
45 Russell, Principles of Mathematics, 80-81. Cf Jean François Lyotard (1988 [1983]), The Differend, Phrases in Dispute, translated by George Van Den Abbeele, (Manchester: Manchester University Press), 6. 
46 Donna Haraway (1988), "Situated Knowledges: The Science Question in Feminism and the Privilege of Partial Perspective," in Feminist Studies, vol 14, no 3, 575-99. divergence would collapse and a new universal statement about matter being 'thus' would re-emerge. However, this would be exposed to the very method of falsification that had brought it back in the first place, thereby preventing any absolute claim. Therefore, divergence is undissolvable not because it cannot be negated, as Cartesian doubt or Meillassoux's fact, but because it belongs to the syntax of thought. The plural possibilities it opens and the totalisation it forbids mark indelibly the system of knowledge, distributing possible and impossible questions.

This circle of refutability is neither vicious, nor subjective. In fact, far from being a paradox, it provides a peculiar form of objectivity beyond binaries. Diverging theories are indeed part of knowledge's history and the evolution of its questions. The pattern given to knowledge by the history of conjectures and refutations situates it; it provides a form of material orientation neither guaranteed externally nor projected virtually. However, this differs from the physical embodiment invoked by Haraway, where gender or technology would determine the dimensions of scientific observation externally. ${ }^{46}$ Rather the body of knowledge is structured by the specific historical distributions of the possibility and impossibility of its claims. The history of this body constitutes the conditions and dimensions for what can be thought as well as how it can be thought. This unavoidable practice of deducing from existing knowledge only on the base of existing knowledge introduces a metastable rather than transcendent or virtual image of thought; one constantly evolving and reconfiguring its finite patterns. Thus, divergence is neither a self-evident nor a mental object, but belongs to the very language used to explore and explain the world. As such, it orients and shapes knowledge. It is a dimension of thought.

It now becomes clear that we are forced to think thanks to rather than despite of this undissolvable contingency. That is, the divergence between epistemology and ontology generates a tension inside knowledge that forces us to think because it is undissolvable and-at the same time-enables thought because its contingent distribution defines its dimensions. It introduces an undissolvable marker in the system of knowledge, which necessitates thought while remaining entirely contingent. Stengers' diplomacy or Latour's empiricism could not reach this far. The undissolvable contingency of asymmetry is not 
an object entertained by knowledge nor marks knowledge as a fact that has a grip on the mind. More simply, there is no way to think past it. Instead, by reducing the undissolvability of uncertainties to a matter of fact, that is to objects of knowledge, Latour's position is prone to the manipulation that finds these facts inside knowledge only to turn them into autonomous objects independent of thought, reinstating the absolute. ${ }^{47}$ The problem is in fact even greater: the exhortation to abandon a priori concepts, to be open, choosing not to know, perpetuates the very practice of epistemological cleansing Latour had hoped to avoid.

\section{Refutations and repetitions}

What is encountered in the silence left by the asymmetric divergence in the place of universal statements is not an ontological unsayable, but a finite organisation of thought according to the possibilities expressed by the mathematical syntax; the distribution and orientation of the onto-epistemological dimensions of the universeknowledge. There were the possible ends the impossible does not begin, there is simply nothing to feel or think. Asymmetry marks an impossibility, which does not separate knowledge from ignorance, the known from the yet to be discovered. Instead, it defines patterns of possibility as the material and corporeal dimensions along which knowledge can develop. The body of knowledge is the condition for knowledge. Thought folds itself along these distributions of possibility and impossibility.

Here, with an entirely unorthodox interpretation, Popper's theory of falsifiability can help understanding the problem at stake. The circularity of refutations highlighted earlier could leave linear ontology entirely stranded, perhaps even vulnerable to self-annihilation. Yet, moving Popper's refutability well out of the space of transcendental inductivism in which it was conceived and relocating it in the peculiar space of incompleteness opened by Prigogine and Stengers' asymmetry, the notion of conjectures and refutations provides a radical alternative to a logic of knowledge built on the aseptic ground of absolute necessity.

In a system of which it is not possible to prove or name the totality, as asymmetry, every apparent certainty is contingent. Popper's great intuition was indeed to begin thinking from the complex and
47 Latour, Reassembling the Social, 87-120. The absolutist interpretation of Latour's fact is formulated by Harman in his Prince of Networks. 
48 Deleuze, Difference and Repetition, 161-62. See also Gottfried Wilhelm Leibniz (2007 [1709]), Theodicy: Essays on the Goodness of God, the Freedom of Man and the Origin of Evil, Austin Farrer (Ed.), translated by E.M. Huggard, (Charleston, SC: Bibliobazaar). vulnerable finitude of present knowledge rather than from foundational axioms. As a theory is never true but only robust, in so far as it resists attempts to invalidate it, knowledge does not represent a fact but is instead a projection, a metastable statement both adapting and susceptible to be disproved. Refutation is a negation entrusting the experimental practice with the metaphysical authority of noncontradiction. However, asymmetry complicates this. As was seen, the equally valid but not equivalent formulations of the mathematical syntax undo the notion of an ultimate matter and of a language able to name it. Thus, the empirical proof loses its apodictic value. What is left are heterogeneous statements whose validity is local and finite. In fact, the asymmetry exposed by Prigogine and Stengers takes the question of knowledge out of an a priori ontological space designed as a binary true-false map, and moves the vulnerability of existing knowledge into a regime of distributions determined by open and closed possibilities: the not-yet-refuted as the open possible and the refuted as the closed impossible.

What emerges here is an intersection between Popper's robustness and Leibniz' compossibility by way of Deleuze's speculative interpretation of concepts. ${ }^{48}$ Openness, the robust theory yet to be refuted, is nothing but repetition. The possible is not an a priori space to be filled, but simply the uninterrupted iteration of existing propertiesin this case the epistemological parameters of the question asked. Possibility, as openness, is a not yet interrupted speculative series. It is the question that can still be posed and still generates answers, no matter how partial or prone to falsification; a theory that continues to find new opportunities to gather data and expand its relevance. Possibility as the not-yet-refuted, the mere contingent openness of iterability, radically differs from the actualisation of the virtual and does not have any metaphysical authority. Its legitimacy rests on the materiality of its historical repetitions. Conversely, the negativity of the impossible is not negation, nor it is imposed externally or empirically. The impossibility expressed in the refutation is an instance of incompossibility in an open series of iterations. A refuted theory is a set of conjectures that has been counteractualised by the possibility of another set of conjectures.

Moreover, as asymmetry is not expressing an either-or exclusion, but the divergence of equally valid possibilities, that is a refutation of the universal by the alternative proof of the local, what is coming to the 
fore is that possibility and impossibility are not binary opposites. This brings about a reversal of the negative value of undecidability. A conjecture is a question that can continue being asked, a series repeating uninterrupted, a not yet decided statement-possibility. Refutation, on the other hand, is a decided statement, a series interrupted and no longer repeating-impossibility. That is, on the one hand refutability, as undecided repeatability, indicates an affirmative interpretation of incompleteness: the ability to repeat the conjecture as the projection of an expectation which is not yet decided. Thus, possibility here is not the expression of an a priori concept but just a name for the open horizon of incompleteness. As a promise of decidability, it is not yet a something but mere openness, the nonexistence of a totalising ontological perimeter-and as such it is zero. The refuted on the other hand, as the interrupted repetition, is a concrete instance of incompossibility. Yet, this impossibility does not coincide with the exclusion of the contradictory but with the decided. Its negation is a local determination. It identifies a fixed point, a mark in thought. As the decided and the certain, it is a positive-and as such it is one. The binary opposition of true and false is thus replaced by the intersection of series that can continue iterating and series that find no opportunity for further iterations.

Language is slippery here. Openness and closure belong to an ontology modelled on the image of space. Yet, the possible and the impossible do not follow such metaphysical map laid out a priori, nor fill an ontological perimeter defined by an identity or a virtual horizon. The possible is not following an open channel and the impossible is not the encounter with a blocked passage. Rather the opposite: passages open or close when repetitions continue or stop. Refutability is an entirely contingent logic of repetitions and counteractualisations. This turns western thought inside out. Knowledge is not a dichotomic distribution of true and false. Its logic is no longer concerned with the self-evidence that guarantees certainty, foundations or absolute objects, but with local distributions on the surface of the present. As the also possible expressed by the formulation proposed by Prigogine does not enter in a competition of mutual exclusion with other theories, it expands the front of falsifiability, it enriches the conjecture. For Popper "the more the laws of nature prohibit, the more they say." 49 But this is still a linear accumulation of information. Instead, the
49 Popper, The Logic of Scientific Discovery, 19. 
information entropy proliferating in these highly complex compossible combinations includes the history of their moments of bifurcation. That is, Deleuze's speculation must include the refuted. The history of refutations forms part of knowledge as much as it shapes it. Origins do not explain knowledge. Past aseptic foundations or absolute objects, feedback loops within existing contingent historical knowledge define the logic of knowledge systems as an ecological equilibrium of opening and closing possibilities. They produce a metastable multidimensional pattern without metaphysical depth. Deleuze invoked a "geometry of sufficient reason" to replace the a priori space of universal concepts..$^{50}$ This can be accepted with the caveat that the thought that retraces the path of emerged concepts does not point to the isotropic horizon of pure difference, but retains the diverging conceptualisations of the question. Asymmetry therefore acts as an ontological marker, not an object or a phenomenon but a turn in phenomena, a fold of thought as well as the world; a dimension that orients the body of thought along what is still possible and away from what has become impossible. This marker must not be imagined as the coordinates of a new ground or a differential space. It belongs to the realm of universal constants. It is a material dimension in the logic of thought and knowledge. Well before arguing about a world in itself versus a world for us, the theory of knowledge, knowledge and the object of knowledge are part of the same phenomenon and the same event. In this light, markers dictate the dimensions of knowledge rather than being objects of knowledge defined by external factors. They are moments where the universe of sense takes shape. They mark knowledge's materially; they are the shape of its body, the rhythm of its processes.

\section{The knowledge system}

The question about the logic of epistemology here has shifted. No longer a problem of self-evident truth, of concepts able to support the edifice of knowledge or of undissolvable objects, but a distribution of possible and impossible avenues as dimensions for thought. What forces us to think also determines how we think; it is not dictated by a metaphysical, external and unaccountable authority, but precisely the opposite. It is a divergence that shapes knowledge unavoidably, because it shapes the dimensions along which it is possible to think. 
What forces us to think is how we are forced to think-how thought is distributed. We are forced to think by a plurality of contingent conjectures and their local refutations. Yet, what forces us think is not this plurality erected to a metaphysical entity or necessity, rather it is how different contingent conjectures diverge or clash locally that demands us to think. The contingent question about the world being thus rather than otherwise overtakes the absolute question about the reason for passing from nothing to something.

The self-evidence of absolute necessity does not require us to think. In fact the opposite, self-evidence is precisely what cannot be questioned, what has done the thinking for us already, so that we can go on obediently deducing and filling the grid that the image of thought has laid out for us a priori. The self-evidence of foundations does not hold us responsible for our choices or require that we care or be creative. The tabula rasa, the image of idealised beginning, the a-dimensional point from which thought should start always anew, always from scratch, the abstract space-time without geographies or histories, as well as the pure durational consciousness or the absolute autonomy of the object all censor the information and organisation that structure the present and hollow existence of its sense. Asymmetry shows that this aseptic ontological ultimate cannot be inhabited. The pure state, cleansed of all local and contingent determinations does not give us access to Being, it gives us nothing. Cleansed of its history, the pure idealisation does not provide access to consciousness, it cancels the human. In the idealised, autonomous or virtual state there is no human. Before the encounter and its history there is no human. The event of sense is unpierceable from inside and has no outside. Perhaps is then worth considering if Deleuze's invocation for a "thought without image" shouldn't in fact be turned around. Thought is a plurality of images, distributions and organisations. Yet, one not a priori, structured by a logic of deduction, rather the product of contingent processes, where the patterns of repetition are the very dimensions of thinking. 